\title{
Sartículos
}

\section{Posiciones situacionistas sobre el Arte}

\author{
María Fuentes Carrasco \\ Investigadora vinculada a la Universidad de Málaga
}

RESUMEN

La Internacional Situacionista (1957-1972), grupo liderado por Guy Debord, dejó un influyente legado teórico y crítico. En este trabajo repasamos las tesis situacionistas sobre el arte en general, la vanguardia histórica y el arte coetáneo.

PALABRAS CLAVE: Arte Contemporáneo/ Vanguardias/ Teoría del Arte.

Situationism Positions about Art.

ABSTRACT

The Situationist International (1957-1972), group under the leadership of Guy Debord, left an influential theoretical and critical legacy. This article revises the situationist thesis about art in general, european avant-garde and coeval art. KEY WORDS: Contemporary Art/ Avant-garde/ Art Theory.

\begin{abstract}
"Nos atañe a nosotros solos, artistas y científicos de una misma poesía, crear la tierra de otra manera, los océanos, los animales, el Sol y las otras estrellas; el aire, el agua y las cosas. Y nos atañerá el soplar sobre la arcilla para dar nacimiento a un nuevo hombre, hecho únicamente para el reposo del séptimo día".

Giuseppe Pinot Gallizio,

Discurso sobre la pintura industrial y sobre un arte aplicable, 1959.
\end{abstract}

La Internacional Situacionista ${ }^{1}$ (IS) nació durante un congreso celebrado en la localidad italiana de Cosio d'Arroscia en julio de 1957, a partir de la fusión de varios movimientos de vanguardia europeos surgidos después de la Segunda Guerra Mundial: la Internacional Letrista (Debord, Bernstein), el Movimiento Internacional para una Bauhaus Imaginista (Pinot Gallizio, Jorn, Olmo, Simondo, Verrone) y el Comité Psicogeográfico de Londres (Rumney). La francesa Internacional Letrista fue la principal generadora de conceptos y actitudes; por ejemplo, la deriva o el urbanis-

\footnotetext{
* FUENTES CARRASCO, María: "Posiciones situacionistas sobre el arte" ,en Boletín de Arte, n²9, Departamento de Historia del Arte, Universidad de Málaga, 2008, págs. 393-407.

1 Sólo puedo empezar agradeciendo a la profesora Natalia Bravo Ruiz el descubrimiento de la IS, que desembocó en la redacción de este artículo en la primavera de 2004.
} 
mo unitario proceden de ella. Fundada y capitaneada por Guy Debord y compuesta de poetas, artistas y cineastas que habían pertenecido al Movimiento Letrista de Isodore Isou, estuvo activa desde 1952 en París. Dos años más tarde iniciaron la publicación, primero semanal y después mensual, de Potlatch ${ }^{2}$, el boletín del grupo que sería asimilado por la Internacional Situacionista a partir de su fundación.

La Internacional Situacionista, con una "vocación internacional al viejo estilo revolucionario" 3 , tuvo un total de 70 miembros de diversos países, sobre todo europeos (franceses, holandeses, belgas, alemanes, daneses, italianos y británicos), pero también algunos argelinos (Mohamed Dahou, Abdelhafid Khatib, etc.), estadounidenses (como Robert Chasse o Bruce Elwell)... La mayoría fueron víctimas de las sucesivas purgas (constantes desde la fundación hasta la autodisolución del grupo), bien mediante la expulsión, o bien, mediante la renuncia voluntaria. Normalmente la exclusión se debía a desacuerdos ideológicos (muchas veces precipitados por una concesión al stablishment), algo lógico si tenemos en cuenta la diferencia entre los enfoques de cada grupo y/o individuo. En los casos de Asger Jorn (que dimitió en abril de 1961 por su creciente fama) y Michèle Bernstein (que renunció en junio de 1967), la colaboración con la IS continuó; sin embargo, son una excepción. En su esfuerzo por mantener una posición radical e intolerante con la sociedad del espectáculo, Debord se configuró como un controvertido cancerbero; de hecho, ha sido muy criticado por ello y no deja de ser irónico el paralelismo que se puede establecer entre él y su odiado André Breton. Si bien fue indudablemente el alma de la IS, las aportaciones teóricas y prácticas de otros fueron también esenciales. Así, por ejemplo, Asger Jorn (que produjo una serie de influyentes ensayos y además una interesante obra pictórica en torno al concepto de détournement), Constant (creador del proyecto urbanístico utópico de New Babylon) o Giuseppe Pinot Gallizio y su "pintura industrial".

La revista Internationale Situationniste 4 fue el principal instrumento de expresión teórica del grupo, incluyendo manifiestos, ensayos, noticias internas, comentarios críticos sobre la actualidad... Además, algunas de las secciones nacionales publicaron sus propias revistas, de vida más o menos larga: Spur (sección alemana, 1960-1962, 7 números), Situationistisk Revolution (sección escandinava, 1962-1970, 3 números), The Situationist Times (edición internacional, 1962-1964, 6 números), Der Deutsche Gedanke (sección centroeuropea, 1963, 1 número), Heatwave (sección británica, 1966, 2 números), Situationist International (sección estadounidense, 1969, 1 número), Internazionale Situationista (sección italiana, 1969, 1 número), etc.

\footnotetext{
2 Los textos completos publicados en Potlatch están traducidos al español: Potlatch. Internacional Letrista (19521959), Madrid, Literatura Gris, 2001. El nombre de la revista, como explica el mismo Debord en el último número, procede de "una forma de circulación precomercial de bienes entre los indios de América del Norte basada en la reciprocidad de regalos suntuarios" (DEBORD, G. E., "El papel de Potlatch antes y ahora", en Potlatch... op. cit., pág. 124, originalmente publicado en Potlatch $n^{\circ} 1$ de la nueva serie ( $n^{\circ} 30$ y último), julio de 1959.

3 LÓPEZ ROJO, A.: "Situacionistas: arte, política, urbanismo", en Lápiz no 128-129, pág. 113.

4 Internacional Situacionista. Textos completos de la revista Internationale Situationniste, 3 vols., Madrid, Literatura Gris, 1999-2000. Hay otras compilaciones parciales de textos situacionistas traducidos, que citaremos en su caso. La revista tuvo doce números entre 1958 y 1969.
} 
Asimismo, se realizaron numerosos panfletos, postales propagandísticas, conferencias, colaboraciones en prensa, etc., a lo que hay que añadir la actividad individual de cada uno de los miembros (libros, películas, exposiciones, etc.). Se organizaron en total ocho congresos de la Internacional Situacionista -el último en septiembre de 1969- en diferentes ciudades europeas.

La Internacional Situacionista no es reducible simplemente a un movimiento artístico $^{5}$. Es también un movimiento revolucionario que, eso sí, concede un papel central a lo artístico, en sentido amplio, en sus luchas, ya que éstas se desarrollan en el plano de la propaganda y de la educación de las masas. Como escribió el mismo Guy Debord, la Internacional Situacionista "puede verse como una vanguardia artística, como una investigación experimental de modos posibles de construir libremente la vida cotidiana y como una contribución al desarrollo teórico y práctico de una nueva contestación revolucionaria"6. En cualquiera de sus facetas, la IS tuvo un evidente talante utópico y revolucionario, en el sentido de que pretendía cambiar el mundo a través de sus actuaciones; las prácticas situacionistas querían transformar la vida cotidiana. Así, los situacionistas no sólo criticaban su (nuestro) presente y buscaban nuevas estrategias revolucionarias, sino que también describían el futuro de la humanidad liberada del trabajo, combinando con cierta ambigüedad la crítica, las realizaciones prácticas y la utopía7. Como bien señala Simon Sadler8, los situacionistas se vieron en cierta forma atrapados en una paradoja: las prácticas situacionistas crearían la situación revolucionaria que es por su parte esencial para que estas prácticas se realizaran verdaderamente. Su confianza en el poder del arte y de la arquitectura para influir en otras esferas y ese proyecto de "el dépassement de l'art, la disolución entre todas las barreras entre el arte y la vida"9 (característico sobre todo de los primeros años) es más propia de las vanguardias históricas que del panorama posmoderno.

Es difícil, si no imposible y falsificador, separar lo político y lo artístico en el grupo, puesto que los situacionistas mismos luchaban contra el aislamiento entre las distintas esferas, como veremos más adelante. Carlos Verdaguer ${ }^{10}$ distingue una primera etapa en la que el ámbito principal de actuación fue el artístico (1957-1962), seguida de un giro hacia lo político por parte de la sección principal, la francesa, que se sepa-

5 Hasta qué punto lo son el dadaísmo y el surrealismo, así como las demás vanguardias históricas, aún se sigue discutiendo. El punto de vista más formalista se opone a aquel que reniega de la recepción acrítica, meramente estética, de las propuestas radicales de la vanguardia. A pesar del interés del tema, escapa a las intenciones de este trabajo, de forma que no profundizaremos más en él.

6 DEBORD, G.: "The Situationists and the New Forms of Action in Art and Politics", 1963. Traducción inglesa obtenida en www.cddc.vt.edu/sionline (abril 2004).

7 Es curioso que "utópico" se usara entre los situacionistas casi como un insulto; en sus textos se reitera lo realizable de sus propuestas.

8 SADLER, S.: The Situationist City, Cambridge y Londres, Mass y The MIT Press, 1999, pág. 157.

9 ANDREOTTI, L.: "Introducción: la política urbana de la Internacional Situacionista (1957-1972)", en ANDREOTTI, L. y COSTA, X. (eds.): Situacionistas: arte, política, urbanismo, catálogo de exposición, Barcelona, MACBA, 1996, pág. 13.

10 VERDAGUER, C.: "Construir la revuelta. Contexto y orígenes de la Internacional Situacionista (1957-1971)", $B I S n^{\circ} 24$, otoño 1999. Una versión anterior del mismo artículo fue publicada en Arquitectura Viva $n^{\circ} 51,1997$. 
ró definitivamente de otras secciones nacionales e individuos más vinculados a la faceta artística (Constant, las secciones alemana y danesa, etc.). De cualquier forma, la IS nació como respuesta tanto al contexto político (al capitalista avanzado de Occidente pero también al socialista de la U.R.S.S. o de China y de la izquierda oficial europea, estalinista), como a la situación del arte, la arquitectura y el urbanismo de la época.

A lo largo de los años de actividad, los situacionistas tuvieron choques con el sistema judicial de diversos países (Dinamarca, Estados Unidos, Gran Bretaña, Francia, Alemania...). Críticos con todo, se les suele reconocer como uno de los detonadores del 68 francés, en el que tuvieron un papel activo (dos años antes, se habían involucrado en la revuelta estudiantil en la Universidad de Estrasburgo). De hecho, participaron en la noche de las barricadas en la calle Gay-Lussac (10 de mayo) y, aliándose con los Enragés, constituyeron primero el Comité de Ocupación de la Sorbona (14 de mayo) y después el Consejo de Mantenimiento de la Ocupación (17 de mayo), disuelto finalmente el 15 de junio. Los situacionistas quisieron ampliar la revuelta estudiantil más allá del ámbito universitario; además de incluir a algunos trabajadores en el Comité, realizaron un llamamiento para la ocupación de todas las fábricas de Francia (30 de mayo). Pero la revolución se extinguió poco después, con el gobierno gaullista al borde del colapso, cuando los estudiantes volvieron a las aulas y los trabajadores a las fábricas, llamados por la Confédération Générale du Travail y el Parti Communiste Français; los situacionistas y los estudiantes más comprometidos se marcharon exiliados a Bélgica. Unos pocos meses después aparecería la crónica del situacionista René Vienet ${ }^{11}$ y la IS empezó a apagarse poco a poco hasta que, en abril de 1972, Debord y Sanguinetti anunciaron su disolución en "Tesis sobre la Internacional Situacionista y su tiempo"12.

La Internacional Situacionista sin duda ha ejercido una notable influencia en el ámbito de los movimientos revolucionarios de izquierda, especialmente en los anarquistas. Todavía en la actualidad encontramos algunos grupos de inspiración situacionista, como por ejemplo el que edita en Estados Unidos la revista Not Bored! (que posee además una excelente página web con gran cantidad de material gratuito en inglés sobre la IS) ${ }^{13}$ o los numerosos "comités psicogeográficos" -normalmente de vida breve- que han surgido en diversos emplazamientos. Por otro lado, las prácticas situacionistas también han calado en el terreno artístico: en el arte de activismo político, que ha heredado en gran medida la preocupación por el medio urbano contemporáneo ${ }^{14}$; en algunas de las tendencias contemporáneas de la arquitec-

\footnotetext{
11 VIENET, R.: Enragés et situationnistes dans le mouvement des occupations, París, Gallimard, 1968 [traducción española: Enragés y situacionistas en el movimiento de las ocupaciones, Madrid, Miguel Castellote Editor, 1978].

12 Es el capítulo central de DEBORD, G. E. y SANGUINETTI, G.: La veritable Scission dans l'Internationale, París, Éditions Champ-Libre, 1972.

13 La dirección es www.notbored.org

14 López Rojo cita como ejemplo más reciente la deriva de una semana realizada por el artista italiano Fausto Grossi en 1994 "por el Bilbao inmediatamente anterior a su transformación radical encabezada por el metro de Foster y el museo Guggenheim de Gehry", op. cit., pág. 120.
} 
tura (Archigram, high-tech, etc.); en el "apropiacionismo" posmoderno (indudablemente deudor del détournement), etc. Asimismo, la densa teoría situacionista ha sido una clara fuente de inspiración para buena parte de los pensadores franceses de izquierda ${ }^{15} \mathrm{y}$, a través suyo, para el pensamiento sobre la posmodernidad.

A finales de los años ochenta comenzó la recuperación de la herencia situacionista por parte del ámbito académico en Estados Unidos y Francia, que después se extendería por otros países, incluida España. De esta forma, la bibliografía académica sobre el tema es cada vez más amplia y se han realizado varias grandes exposiciones en los últimos años, entre las que destacan On the passage of a few people through a rather brief moment in time: The Situationist International 19571972 (Centre Georges Pompidou de París, The Institute of Contemporary Arts de Londres y The Institute of Contemporary Art de Boston, 1989-1990) y Situacionistas: arte, política, urbanismo (MACBA, 1996). En muchas ocasiones, la Internacional Situacionista se trata desde un punto de vista exclusivamente artístico, y en otras, exclusivamente político, aunque afortunadamente hay enfoques que mezclan ambas perspectivas. Las valoraciones van desde la glorificación hasta el ataque, enfocadas normalmente en la carismática figura de Debord.

En este trabajo nos proponemos profundizar en las posiciones y desarrollos teóricos de la IS sobre arte ${ }^{16}$, en tres direcciones: hacia el pasado (valoración de la vanguardia), hacia el presente (valoración del arte coetáneo) y hacia el futuro (propuestas situacionistas). Podemos encontrar una teoría de la vanguardia y del arte en general (qué es, qué debe ser) implícitos en los textos situacionistas. No hemos seguido un orden cronológico en la exposición, pero hay bastante homogeneidad y coherencia teórica en sus tesis a lo largo de los años. En la selección de textos hemos tenido en cuenta a la Internacional Situacionista como grupo; y aunque los escritos de Debord son probablemente los más ricos y densos, hemos querido utilizar además los de otros situacionistas, así como las editoriales sin firmar de Internationale Situationniste.

\section{EL fRACASO dE LA VANGUARDia.}

Los situacionistas se veían a sí mismos como los verdaderos "herederos universales" del "arte moderno"17. Para que esto fuese así, necesariamente tuvieron que desarrollar una interpretación de éste diferente de la hasta entonces aceptada generalmente. Aunque el enfoque formalista había sido el predominante desde sus inicios, fue a partir de los años cincuenta cuando se consagró definitivamente a manos del crítico estadounidense Clement Greenberg, que impuso además una versión muy

\footnotetext{
15 La relación entre los conceptos de espectáculo de Debord y de simulacro de Baudrillard es quizás el ejemplo más evidente.

16 En el título de este artículo nos hemos permitido parafrasear un texto de Debord, "Posiciones situacionistas sobre la circulación" (1959).

17 "La vanguardia de la presencia" (1963), en Internacional Situacionista... op. cit., vol. 2, 2000. Todos los textos compilados en esta obra que hemos consultado han sido obtenidos en www.sindominio.net (abril de 2004).
} 
simplificada. Así, el valor y el carácter revolucionario del arte de vanguardia residirían en las innovaciones formales y en su progresiva desvinculación de todas las demás esferas, es decir, en la autonomía absoluta que lo liberaría de cualquier consideración extra-estética. No sería hasta los años sesenta y setenta que algunas voces (desde posiciones de izquierda, en la línea de Walter Benjamin) se elevarían para atacar esta perspectiva y hacer hincapié en otros aspectos de la vanguardia, como sus implicaciones sociales y políticas o la voluntad de vincularse a la vida. Los situacionistas se adelantaron en varios años a estas interpretaciones, como ahora veremos.

¿Qué idea de vanguardia tenían los situacionistas? Fundamentalmente, y como era de esperar, política. La vanguardia implica un "aspecto militante" 18 y una voluntad subversiva radical contra la cultura y la sociedad burguesas que la convierten en peligrosa para el sistema (y por tanto conscientemente reprimida). Su valor revolucionario consistió en "destruir todas las convenciones del arte, del lenguaje y del comportamiento", es decir, en su negatividad o, en palabras de Debord, en su "verdad negativa"19 dirigida contra la sociedad donde se desarrolló. La postura situacionista se opone claramente a la formalista (en principio apolítica, pero a la postre conservadora) también, rechazando explícitamente la autonomía del arte, comprendida como independencia absoluta de lo estético frente a todas las demás esferas. La IS se pronunció repetidamente en contra de la especialización y la separación que ésta implica, buscando la supresión del arte y de la política mediante la realización de ambos en la vida. De esta forma, otro de los valores de la vanguardia histórica radicaría en la búsqueda de nuevas "técnicas que sobrepasen el arte" 20 , es decir, en la práctica de un arte experimental (término muy querido por los situacionistas) destinado a la ampliación de la práctica artística más allá del ámbito puramente estético. Si Greenberg hablaba de un proceso de purificación en el que se buscaba "lo que tenía de único e irreductible no sólo el arte en general, sino también cada arte en particular"21, los situacionistas tienen una perspectiva opuesta, esto es, de apertura del arte hacia otros ámbitos y de mezcla de las artes individuales. Por ello es lógico que cuando hablen de vanguardia y de arte moderno, se refieran a las vanguardias de la época de entreguerras, especialmente al dadaísmo y al surrealismo. Sin embargo, el término "vanguardia" no es usado en los textos situacionistas como meramente histórico, es decir, como algo pasado y diferente del presente. Dentro de él engloban generalmente movimientos surgidos después de 1945, sobre todo los que fueron antecesores de la propia IS (por su postura subversiva y por agrupar a muchos de los posteriores situacionistas), como COBRA o el Movimiento Internacional para una

\footnotetext{
18 DEBORD, G. E.: "Informe sobre la construcción de situaciones y sobre las condiciones de la organización y la acción de la tendencia situacionista internacional" (1957), en Potlatch... op. cit., pág. 143.

19 DEBORD, G. E.: "The Situationist and the New Forms of Action in Art and Politics", op. cit.

20 NIEUWENHUIS, C.: "Sobre nuestros medios y perspectivas" (1958), en La creación abierta y sus enemigos. Textos situacionistas sobre arte y urbanismo, Madrid, Ediciones de La Piqueta, 1977.

21 GREENBERG, C.: "Modernist Painting" (1960). La traducción española nos ha sido facilitada amablemente por $\mathrm{M}^{\mathrm{a}}$ Teresa Méndez Baiges.
} 
Bauhaus Imaginista. Así, la IS se considera a sí misma como una vanguardia en términos de igualdad con las históricas o, mejor dicho, como la vanguardia definitiva que viene a realizar lo que las anteriores intentaron. La forma en la que éstas son comentadas pone de manifiesto claramente este sentimiento de continuidad -tan extraño, por otra parte, a lo posmoderno.

Sin embargo, a pesar de sus logros reconocidos, la potencialidad de la vanguardia artística nunca fue realizada: fue "una explosión que nunca ocurrió, que amenazó y amenaza todavía las estructuras de la sociedad"22. En paralelo con "el reflujo del movimiento revolucionario mundial" 23 , las tendencias artísticas verdaderamente subversivas fueron banalizadas, mercantilizadas y falseadas, en fin, neutralizadas por una sociedad burguesa que se protegía de esta manera. Aunque no usen el término, los situacionistas hablan de la institucionalización de la vanguardia, tema que todavía hoy es central en los estudios del arte y la cultura del siglo $X X^{24}$. De cualquier modo (y tocando otro asunto muy debatido hasta la actualidad), la vanguardia fracasó en sus intenciones subversivas y no sólo por la contraofensiva burguesa, sino también por una serie de "errores" internos, que se detallan a través de varios textos.

El futurismo italiano, por ejemplo, adoleció de "puerilidad" en su "optimismo técnico" 25 , lo que lo llevó finalmente a disolverse en el nacionalismo antes de desarrollarse más profundamente. Debord, sin embargo, le concede el mérito de haber llevado a cabo numerosas innovaciones formales (aspecto que no es precisamente el más sobresaliente del futurismo desde el punto de vista actual, que lo considera deudor de las innovaciones cubistas).

El surrealismo es sin duda la tendencia que más atención recibe: es la más cercana geográfica y temporalmente -de hecho, por entonces se mantenían en activo muchos de los surrealistas- al núcleo de la Internacional Situacionista, es decir, la sección francesa. Aunque el surrealismo acertó al afirmar "la soberanía del deseo y de la sorpresa" y proponer "un nuevo uso de la vida", se equivocó al creer "en la riqueza infinita de la imaginación inconsciente"26, cuando, según Debord, en realidad es pobre, repetitiva y monótona. El uso del absurdo para poner de manifiesto la irracionalidad de la sociedad burguesa, encubierta por los "valores lógicos superficiales", tenía una intención subversiva, pero pronto fue asimilado por el sistema. A decir de los situacionistas, a partir de los años 30 ya no aportó nada nuevo y después de 1945 entró en franca decadencia, limitándose su práctica a repeticiones degradadas y estetizadas, vaciadas ya de todo su sentido revolucionario. Precisamente esta es la "amarga victoria del surrealismo", su triunfo en un mundo que pretendía cambiar pero que sigue siendo el mismo. La asimilación no sólo se percibe en el mundo artístico (por ejemplo, en la pintura de Pollock), sino incluso en la ciencia o en las técni-

22 "Cuestionario" (1964), en Internacional Situacionista... op. cit., vol. 2.

23 DEBORD, G. E.: "Informe sobre la construcción de situaciones...", op. cit., pág. 148.

24 Recibe mucha atención, por poner sólo dos ejemplos, en los textos de Frederic Jameson y de Hal Foster.

25 DEBORD, G. E.: "Informe...", op. cit., pág. 143.

26 Ibídem., pág. 144. 
cas empresariales (como el brainstorming). También se les reprocha a los surrealistas el mantenimiento de las artes tradicionales, el realizar un mero "suplemento de la poesía o el arte liquidados por el dadaísmo"27, es decir, se les reprocha su anacronismo y su retroceso conformista, como en el caso de la respuesta a las críticas del poeta surrealista Benjamin Péret ${ }^{28}$.

Si el surrealismo representa en los textos situacionistas a la vanguardia en decadencia, degradada y al servicio de la sociedad burguesa, el dadaísmo bien puede representar la vanguardia también fracasada pero de forma heroica, si bien no se libró enteramente de la asimilación, como luego veremos. En general, Dadá es visto como un punto clave en el desarrollo del arte moderno por su negatividad radical. Los dadaístas no sólo rechazaron todos los valores de la sociedad burguesa, sino que intentaron destruir la literatura y el arte, asestando "un golpe mortal a la concepción tradicional de la cultura"29. Como culminación del papel revolucionario del arte moderno, la radical negación dadaísta ha marcado a muchos de los movimientos artísticos posteriores, pero "hizo necesaria su casi inmediata disolución"30. Los situacionistas, por tanto, comparten la interpretación canónica de este movimiento como esencialmente nihilista, punto de vista que ha sido acertadamente matizado en los últimos años. Porque Dadá fue un fenómeno muy complejo, con manifestaciones muy dispares; frecuentemente contenían algo más que la negación violenta de todo lo establecido, es decir, es posible encontrar en muchas de ellas una afirmación (eso sí, de algo diferente a lo tradicional). De cualquier modo, la importancia que le conceden los situacionistas al dadaísmo de nuevo se adelanta a las interpretaciones de la vanguardia de los años sesenta y setenta (y posteriores). Hoy en día, de hecho, recibe una consideración central y Marcel Duchamp es visto como uno de los principales artistas del siglo $\mathrm{XX}^{31}$.

El funcionalismo (Bauhaus, Le Corbusier...) recibe asimismo bastante atención por parte de los situacionistas, principalmente por dos motivos. En primer lugar, la IS daba gran importancia al urbanismo en sus luchas contra la sociedad del espectáculo. Especialmente en la primera etapa, los situacionistas enfrentan al modelo racionalista de ciudad el "urbanismo unitario", su opuesto en muchos sentidos. En segundo lugar, Constant Nieuwenhuis (el creador de New Babylon, la utópica ciudad situacionista) y sobre todo Asger Jorn (que fue alumno de Le Corbusier) fueron figuras influyentes en el grupo. La actitud ante el funcionalismo es más compleja que el simple rechazo. Asger Jorn, en el texto de 1956 "Sobre el valor actual de la concepción funcionalista" 32 , anuncia en gran medida el talante ante éste de los posteriores

27 "Amarga victoria del surrealismo" (1958), en Internacional Situacionista...op. cit., vol. 1.

28 "La nostalgia por debajo de todo" (1958), en Ibídem., vol. 1. Es la respuesta al texto de Péret "La poesía por debajo de todo" aparecido poco antes en el número 1 de la revista surrealista Bief.

29 DEBORD, G. E. (1957): op. cit., pág. 143.

30 Ídem.

31 En la interpretación formalista de Ortega y Gasset, Greenberg, etc., desde luego esto no era así. Ortega, por ejemplo, califica al dadaísmo de mera "broma" en "La deshumanización del arte" (1925).

32 Incluido en ANDREOTTI, L. y COSTA, X.: Teoría de la deriva y otros textos situacionistas sobre la ciudad, Barcelona, MACBA y ACTAR, 1996, págs. 33-34. 
situacionistas. Si bien se hace inevitable una "revolución contra sus insoportables coacciones", hay una serie de aspectos a conservar, concretamente los formales (determinados por la utilidad y la función). Lo que debe contestarse y superarse es "el programa funcional", la supeditación completa de la estética a la función y el olvido de "la función psicológica del ambiente", que es independiente del aspecto práctico. El urbanismo unitario "no es una reacción contra el funcionalismo, sino su superación: se trata de alcanzar, más allá de lo utilitario inmediato, un entorno funcional apasionante"33. De este modo, muchos de los proyectos situacionistas, incluida la New Babylon de Constant, se pueden considerar como un enriquecimiento semántico del lenguaje racionalista. Por ejemplo, Gilles Ivain habla de la necesidad de llevar a cabo "una ampliación racional de los antiguos sistemas religiosos, de los viejos cuentos y sobre todo del psicoanálisis en beneficio de la arquitectura"34.

Como vemos, los situacionistas toman conscientemente como punto de partida muchos elementos de vanguardias anteriores, especialmente del surrealismo y del dadaísmo (aspecto muy tratado por la historiografía artística sobre la IS). Por ejemplo, el détournement (desvío) situacionista bebe indudablemente del readymade duchampiano y la dérive (deriva), de los paseos dadaístas y surrealistas ${ }^{35}$. Todo esto lleva a la práctica lo que tantas veces afirman en sus textos con respecto al pasado artístico: si bien está muerto, contiene descubrimientos subversivos que pueden ser recuperados. En palabras de Debord, "muchas de las exploraciones parciales del pasado reciente pueden ser rescatadas y llevadas a su verdadera realización"36. Que no es lo mismo que lo que hacen, según los situacionistas, los epígonos del surrealismo o los neodadaístas, repitiendo gestos vacíos al dictado del mercado artístico y en medio de la disolución de la cultura burguesa.

\section{LA CRISIS COMO PUNTO DE PARTIDA.}

En 1967 apareció La sociedad del espectáculo de Guy Debord, probablemente el texto situacionista con mayor influencia posterior, si bien el concepto -aún desdibujado había hecho su aparición en los escritos de Debord (y, por extensión, en los de los demás situacionistas) ya a finales de los años cincuenta. El espectáculo es "la afirmación de la apariencia y la afirmación de toda vida humana, o sea social, como simple apariencia"37. Se caracteriza por el dominio absoluto del capital, de lo económico, de la mercancía, sobre el ser humano. El espectáculo lleva hasta sus últimas consecuencias el lema "divide y vencerás": la separación "es alfa y omega del espectáculo"38. El aislamiento de cada individuo lo condena a la pasividad, la verdadera interacción social ha sido liquidada. También la separación entre los dis-

33 "El urbanismo unitario a finales de los años 50" (1959), en La creación abierta... op. cit., pág. 93.

34 IVAIN, G.: "Formulario para un nuevo urbanismo" (1958), en La creación abierta... pág. 31.

35 Trataremos con más detalle las propuestas y prácticas situacionistas en el último apartado.

36 DEBORD, G. E. (1963): op. cit

37 DEBORD, G. E. (1967): La sociedad del espectáculo, Valencia, Pre-Textos, 2003, pág. 40

38 Ibídem., pág. 46. 
tintos dominios, la división del trabajo y la especialización crecientes son parte de este fenómeno universal. Y es que la sociedad del espectáculo no incluye únicamente al Occidente capitalista, sino también a los países comunistas y subdesarrollados.

No sólo la verdadera vida social ha sido aniquilada por el espectáculo y sustituida por una falsificación: la cultura entera, incluido el arte, ha llegado a su fin. El proceso de autonomía de las distintas esferas, considerado comúnmente desde Kant como uno de los rasgos clave de la modernidad, es para Debord un proceso de disolución, de autoaniquilación, ya que "toda disciplina que se hace autónoma debe caducar, primero como pretensión de explicación coherente de la totalidad social, y después como instrumento particular" 39 . Ante este estado de cosas, sólo caben dos actitudes: la superación revolucionaria de la cultura como esfera separada mediante su realización en la vida (que es la postura situacionista) o la perpetuación de una cultura muerta en el seno del espectáculo. Los situacionistas parten pues, del presupuesto de la decadencia generalizada de la cultura burguesa, como ponen de manifiesto muchos de sus textos, anteriores y posteriores a La sociedad del espectáculo. El arte, la filosofía, etc., se hunden en el vacío: "la descomposición lo ha invadido todo" 40 . La confusión y separación reinantes sirven para perpetuar el statu quo, pues hacen imposible una verdadera crítica global.

No nos puede extrañar por tanto que la valoración situacionista del arte, la literatura y el cine de su tiempo sea muy negativa. Debord, ya en 1957, describía el panorama artístico como dividido entre tres tendencias retrógradas: "la prolongación de las formas aportadas por la crisis dadá-surrealismo [...], la instalación en las ruinas mentales; y finalmente, la vuelta atrás"41. En el primer caso (el de los mediocres epígonos del surrealismo), la repetición de formas artísticas surrealistas y dadaístas se caracteriza por la banalización de éstas, ya que han sido vaciadas de todo su sentido. Las "ruinas mentales" hacen referencia de nuevo al vacío, a la ausencia de contenido. Esta nada puede ser alegremente afirmada (jóvenes novelistas franceses) o bien disimulada a base de "un vocabulario apropiado", como sería el caso de la literatura existencialista o de la pintura abstracta y sus teóricos. Con el retorno al pasado, Debord critica el realismo socialista de los países de la órbita soviética, considerándolo una recuperación anacrónica de "valores culturales del siglo pasado" 42.

En la práctica, estas tres tendencias son difíciles de diferenciar. La pintura abstracta de posguerra es "una nulidad teóricamente complicada"43, pero también se considera como la aplicación de "detalles, aislados y aumentados, tomados subrepticiamente de la masa coherente de aportes surrealistas" 44 , poniendo como ejemplo

39 Ibídem., pág. 153. Aquí también los situacionistas se adelantan: la crítica a la autonomía de cada disciplina es clave en la teoría de la posmodernidad, especialmente en la norteamericana (probablemente como consecuencia de la profunda influencia de Greenberg allí).

40 DEBORD, G. E.: “Informe... pág. 147.

41 Ibídem., pág. 145.

42 Ibídem., pág. 146

43 ídem.

44 "Amarga... op. cit. 
a Jackson Pollock. De la pintura abstracta, los situacionistas rechazan la preocupación por los aspectos formales y la voluntad, pomposa y vacía, de "basarse en la pintura de 'signos puros' incomunicables" 45 . Las intenciones situacionistas, como luego veremos, no podrían ser más opuestas.

En varios de los escritos situacionistas sobre arte se arremete contra el "neodadaísmo". Con este término se refieren a varias cosas distintas. Podemos decir que los situacionistas lo utilizan para designar a todos los imitadores actuales de los hallazgos dadaístas, puesto que, a pesar de su innegable labor destructiva, el dadaísmo ha acabado convirtiéndose "en una escuela reconocida y sus formas han sido transformadas recientemente en una distracción reaccionaria por los neodadaístas". Olvidando la verdad negativa de la vanguardia original, éstos han querido "cargar con positividad (estética) el rechazo plástico expresado previamente por Marcel Duchamp"46. También se califica de neodadaístas a una serie de escritores (Ionesco, Beckett, Duras, etc.) que explotan la destrucción de las formas artísticas llevada a cabo por el dadaísmo.

La mayor parte de las tendencias artísticas de la época recibe despectivos comentarios aquí y allí: la "noveau roman", el "nuevo realismo" y la "nueva figuración", el cine de Godard, la vanguardia estadounidense de posguerra, el Pop Art, etc. Se las tacha, en general, de "disoluciones" que "son siempre más o menos repeticiones que nadie quiere indicar, de algo más viejo" 47 . Y, por supuesto, son posturas que en el fondo están instaladas en el conformismo con respecto al difunto panorama cultural y al próspero marco económico capitalista. La disolución cultural ha llegado tan lejos, según Debord, que vemos a "la publicidad comercial influir cada vez más en los criterios de creación cultural" 48 , de forma que se erigen nuevos ídolos culturales, sin nada detrás excepto las técnicas de venta.

Los críticos literarios y artísticos no se libran tampoco de las invectivas de los situacionistas, que llegaron incluso a realizar acciones de protesta contra un congreso de críticos de arte desarrollado en Bruselas en abril de 1958, repartiendo un comunicado con frases como "iDesapareced, críticos de arte, imbéciles parciales, incoherentes y divididos!"49. Los situacionistas achacan a los críticos la misma responsabilidad (o incluso más) que a los artistas en el mantenimiento del cadáver de la cultura: es "un espectáculo de segundo grado" 50 , ya que el crítico se dedica a desarrollar su papel como espectador pasivo. Desconcertados ante la disolución cultu-

\footnotetext{
45 DEBORD, G. E.: "The Situationists... op. cit.

46 ídem.

47 "La vanguardia de la presencia", op. cit.

48 DEBORD, G. E.: "Informe... op. cit., pág. 147. Debord pone como ejemplo de esto el "fenómeno SaganDrouet". Françoise Sagan y Minou Drouet obtuvieron un gran éxito literario en la Francia de los 50 a edades extraordinariamente tempranas (especialmente Drouet, que triunfó con sus poemas a los ocho años).

49 "Acción en Bélgica contra la Asamblea de los críticos de arte internacionales" (1958), en Internacional Situacionista... op. cit., vol 1.

50 DEBORD, G. E.: "For a Revolutionary Judgment of Art" (1961), traducción inglesa obtenida en www.cddc.vt.edu/sionline (abril 2004).
} 
ral generalizada, o bien adoptan posturas reaccionarias y denuncian el vacío "para preservar su estúpido sueño de retorno a las buenas maneras del pasado" 51 , o bien celebran la disolución si pretenden ser "modernistas".

\section{LA SOLUCIÓN SITUACIONISTA.}

El panorama de la sociedad del espectáculo era desolador. Sin embargo, todavía había esperanza en la minoría verdaderamente vanguardista que, aunque dispersa, subsistía. Como cabeza de una supuesta tendencia revolucionaria general, la Internacional Situacionista pretendía agrupar y dar coherencia a ésta. Así, por ejemplo, frecuentemente apoyaban acciones ajenas al grupo, calificándolas de (inconscientemente) situacionistas, ya que "el papel de las corrientes de vanguardia, dondequiera que aparezcan, es [...] ayudar a unificar tales grupos y las bases coherentes de su proyecto" 52 .

Así pues, la Internacional Situacionista quería actuar como detonador de la revolución definitiva. Sin embargo, buscó un modelo diferente al soviético o al chino. Los situacionistas vieron en las sociedades comunistas una alienación similar en el fondo a la del capitalismo occidental. La labor de la IS no tendría lugar en el campo de la infraestructura económica, sino en la superestructura cultural. Las condiciones de producción ofrecían unas nuevas posibilidades con respecto a las cuales la acción política revolucionaria se había quedado retrasada. La mecanización creciente del trabajo estaba produciendo un aumento del tiempo libre del proletario. $Y$ este tiempo libre se había convertido en el principal campo de batalla, ya que la clase dominante (la burguesía) se servía de él para generar "un vasto sector industrial del ocio, que es un incomparable instrumento de embrutecimiento del proletariado" 53 , esto es, de alienación. De esta forma, la IS inicia "la batalla del ocio"54 intentando convertirlo en un arma de liberación y de concienciación de clase. La sociedad futura que resultaría de la revolución estaría caracterizada por la conversión de todo tiempo en tiempo de ocio, puesto que la producción sería realizada por máquinas. Siguiendo al famoso sociólogo Johan Huizinga, el homo ludens sustituiría al homo faber.

¿Con qué acciones lograrían los situacionistas su objetivo de despertar al mundo? ¿Cómo liberar el ocio de la alienación? El núcleo de las propuestas situacionistas, al menos en los primeros años, es el urbanismo unitario, entendido como unión de todos los medios artísticos y extra-artísticos que intervienen en "una composición integral del medio"55 (pintura, cine, arquitectura, graffiti, iluminación, etc.). Una especie de arte total que, sin embargo, quiere superar lo artístico. Esta superación del arte vendrá dada por la supresión de éste, que es lo mismo que su realización en la

51 "El sentido del deterioro del arte", en Internacional Situacionista... op. cit., vol. 1.

52 DEBORD, G. E.: "The Situationists..., op. cit.

53 DEBORD, G. E.: “Informe... op. cit., pág. 153.

54 Ibídem., pág.154.

55 Ibídem., pág. 152. 
vida. Se trata de la construcción de situaciones o "construcción concreta de los ambientes momentáneos de la vida y su transformación en una cualidad afectiva superior" 56 , de forma que los situacionistas pretenden intervenir tanto en los elementos materiales que nos rodean como en los comportamientos. Con este fin surgen la deriva, el détournement o desvío, la psicogeografía, el cine situacionista, la pintura industrial o New Babylon. Si bien son poca cosa comparados con el objetivo último (cambiar el mundo, transformar la vida cotidiana). Estas realizaciones parciales son aceptables a corto plazo, aunque se desarrollen dentro del marco de los "medios de expresión cultural" 57 comunes, marco que en última instancia debía ser destruido.

Las actividades de la IS apuntaban pues a un arte experimental y crítico, cargado de sentido y, al menos teóricamente, no orientado a la producción de obras de arte. Éstas serían sustituidas por la creación de situaciones, creación colectiva, cotidiana, constante, efímera, antiutilitarista, basada en el juego y más allá de las caducas "artes individuales"58. Sin embargo, la situación acabaría siendo un ideal casi inalcanzable en su oposición perfecta al espectáculo y su realización total en lo cotidiano. Los mismos situacionistas confesaban en 1963 que "la IS está aún lejos de haber creado situaciones"59.

De esta forma, a pesar de la insistencia en que sus propuestas eran factibles, apenas nada se llevó a cabo. Un buen ejemplo es la proyectada intervención en el Stedelijk Museum de Ámsterdam, consistente en la transformación de dos salas del museo en un laberinto y la deriva simultánea de tres grupos por el centro de la capital holandesa. Aunque incluso se fijó una fecha para la ejecución (mayo de 1960), finalmente la Internacional Situacionista desistió del proyecto por el peligro de comprometerse, de ser coartada en su libertad por terceros ${ }^{60}$. Este miedo a la contaminación, a verse integrados en el decadente sistema del espectáculo, fue constante durante la existencia de la IS y explica las continuas exclusiones y los duros ataques contra los "falsos situacionistas". Este grupo está compuesto en su mayor parte por antiguos integrantes expulsados que continuaron su actividad al margen de la ortodoxia situacionista: Constant, los "nashistas"61, etc. También se arremetió contra los imitadores -supuestos o reales- de las propuestas situacionistas, ya que "la victoria de la Internacional Situacionista en materia de teoría obliga ya a sus adversarios a disfrazarse de situacionistas"62. De hecho, se interpreta el happening neoyorquino como un intento de construir situaciones basándose en la miseria cuando las verdaderas "no pueden construirse más que sobre la base de la riqueza material y espiritual" 63 .

56 Ibídem., pág.154.

57 DEBORD, G. E.: "The Situationists and the New Forms of Action in Art and Politics" (1963), op. cit.

58 DEBORD, G. E. y NIEUWENHUIS, C.: "Declaración de Ámsterdam" (1958), en Internacional

Situacionista... op. cit., vol. 1, pág. 66.

59 "La vanguardia... op. cit.

60 Todo el asunto se explica en "Die Welt als Labyrinth" (1960), en La creación abierta y sus enemigos... op.

cit., págs. 124-128, donde también se describe detalladamente el proyecto.

61 Los "nashistas" son los integrantes de la disidente sección escandinava, liderada por el danés Jorgen Nash, hermano de Asger Jorn.

62 "La vanguardia de la presencia", op. cit.

63 ídem. 
Otro punto interesante con respecto a la Internacional Situacionista es su consideración como la última vanguardia 64 . Esto casa, por ejemplo, con la tendencia actual que extiende la modernidad hasta los años sesenta, momento de inflexión que sustituye a 1945 como inicio de lo contemporáneo (o, si se prefiere, de lo posmoderno). Sin duda, la Internacional Situacionista tiene mucho de la vanguardia histórica en sus planteamientos, en su talante, en sus objetivos. Sin embargo, es posible detectar también una serie de rasgos de corte posmoderno. Por ejemplo, el détournement (desvío) y la deriva tienen claros antecedentes vanguardistas. El primero, definido por Debord y Gil J. Wolman en 1956, en "Modo de uso del desvío"65, consiste en la descontextualización de fragmentos preexistentes (de textos, de cuadros, de películas, de ciudades, etc.) para insertarlos en una nueva obra, proceso mediante el cual se transforma su sentido con intenciones propagandísticas. Remite, pues, claramente al collage y al ready-made.

La deriva, por su parte, es "una técnica de paso prematuro a través de ambientes variados [...] íntimamente ligada al reconocimiento de efectos de naturaleza psicogeográfica y a la afirmación de un comportamiento lúdicoconstructivo"66. Sus precedentes han sido señalados frecuentemente por la historiografía. En primer lugar, tenemos la visita que el grupo dadaísta parisino organizó "a los lugares más banales de la ciudad"67 el 14 de abril de 1921. El mismo Debord cita -considerándola un fracaso- la deambulación surrealista organizada en mayo de 1924 por Breton, Aragon, Morise y Virac, que realizaron a campo abierto entre las ciudades de Blois y Romorantin. Pero más que con esta única deambulación efectiva, la deriva situacionista tiene más que ver con los paseos que muchos de los surrealistas llevaban a cabo por los barrios marginales y periféricos de París y de las descripciones que Louis Aragon (Le paysan de Paris, 1926) y André Breton (Les pas perdus, 1924, y Nadja, 1928) hacen de estos larguísimos vagabundeos en sus novelas. Con sus raíces en la flânerie finisecular, estos itinerarios surrealistas buscan la realidad oculta e inconsciente de París (el escenario predilecto que compartirán con los situacionistas) y la consecución del extrañamiento, como los situacionistas buscaban el desconcierto. Mirella Bandini señala que Breton, en La Clé des Champs (1953), anuncia la cartografía situacionista, ya que "prevé, en este sentido, un mapa imaginario e individual de la ciudad"68 en el que las zonas se pintarían de negro, gris o blanco según la atracción o repulsión que provocasen en el sujeto.

\footnotetext{
64 Por citar sólo dos ejemplos, ésta es la tesis fundamental de PERNIOLA, Mario.: I situazionisti. II movimento che ha profetizzato la "Società dello spettacolo", Roma, Castelvecchi, 1998 y de MÉNDEZ BAIGES, Ma T.: "Un intento de revisión del arte de los sesenta: la Internacional Situacionista como última vanguardia", en Actas del XIII Congreso del Comité Español de Historia del Arte, Granada, CEHA, 2000, págs. 559-566. 65 DEBORD, G. E. y WOLMAN, G. J.: "Modo de uso del desvío" (1956), en Potlatch... op. cit., págs. 135-140. 66 DEBORD, G. E. : "Teoría de la deriva" (1956), en La creación abierta y sus enemigos... op. cit., págs. 61-69. 67 CARERI, F.: Walkscapes: El andar como práctica estética, Barcelona, Gustavo Gili, 2002, pág. 68. Breton y Aragón participaron junto con otros artistas (Péret, Eluard, Tzara, Soupault, etc.).

68 BANDINI, M.: "Referentes surrealistas en las nociones de deriva y de psicogeografía del entorno urbano situacionista", en ANDREOTTI, L. y COSTA, X. (eds.), Situacionistas... op. cit., pág. 43.
} 


\section{2. artículos Posiciones situacionistas sobre el Arte}

Los puntos en común son evidentes, pero no hay que olvidar que ambas prácticas conectan no sólo con el pasado moderno, sino también con la contemporaneidad (apropiacionismo, activismo, etc.). Otro aspecto que separa a la IS de la vanguardia histórica y la acerca a sus tendencias coetáneas es la apropiación completamente consciente de los precedentes. Más aún, los situacionistas no sólo querían "apropiarse de todo el radicalismo de [...] la poesía y el arte modernos"69, sino que también instaban a la apropiación de formas pop (cómic, graffiti, arte kitsch) y de técnicas coetáneas, como la action-painting. Por otro lado, si bien es verdad que el arte de vanguardia no fue ni mucho menos tan autónomo como pretendía Greenberg, no es menos cierto que el rechazo radical de la autonomía artística ha sido una constante en el panorama posmoderno. Difícilmente podemos establecer en qué lado se sitúa la IS, si en la modernidad o en la posmodernidad, y menos aún teniendo en cuenta que las definiciones de ambas son inestables y se siguen discutiendo.

Desde nuestra perspectiva actual, la posición de la Internacional Situacionista se dibuja como imposible: ¿Cómo mantenerse fuera y dentro del sistema simultáneamente? ¿Cómo mantener la pureza y a la vez influir en la sociedad? El 68 francés fue, quizás, el gran éxito y el gran fracaso de los situacionistas, una explosión que se quedó en apenas nada. Por otra parte, tampoco ha podido librarse de la asimilación (por la academia, por el museo, por el sistema artístico) que tanto temieron. Y para la Internacional Situacionista ése es el verdadero fracaso.

69 DEBORD, G. E.: "The Situationists... op. cit.. 
